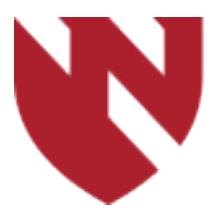

October 2021

\title{
Experience treating electrical storm using an ultrasound guided stellate ganglion blockade
}

\author{
Thomas A. Nicholas IV \\ University of Nebraska Medical Center \\ Levi Zehr \\ UNMC \\ Han-Jun Wang \\ University of Nebraska Medical Center \\ Daniel R. Anderson \\ University of Nebraska Medical Center \\ Steven J. Lisco \\ University of Nebraska Medical Center
}

Tell us how you used this information in this short survey.

Follow this and additional works at: https://digitalcommons.unmc.edu/gmerj

Part of the Anesthesiology Commons, Cardiology Commons, Critical Care Commons, and the Higher Education Commons

\section{Recommended Citation}

Nicholas, T. A., Zehr, L., Wang, H., Anderson, D. R., , Lisco, S. J. Experience treating electrical storm using an ultrasound guided stellate ganglion blockade. Graduate Medical Education Research Journal. 2021 Oct $04 ; 3(1)$.

https://digitalcommons.unmc.edu/gmerj/vol3/iss1/4

This Original Report is brought to you for free and open access by DigitalCommons@UNMC. It has been accepted for inclusion in Graduate Medical Education Research Journal by an authorized editor of DigitalCommons@UNMC. For more information, please contact digitalcommons@unmc.edu. 


\title{
Experience treating electrical storm using an ultrasound guided stellate ganglion blockade
}

\author{
Abstract \\ Introduction: Electrical storm is a life-threatening condition in an often medically complex patient \\ population. Pharmacologic ultrasound-guided stellate ganglion blockade is a treatment option in \\ combination with maximized systemic antiarrhythmic medications. There is an emerging body of case \\ reports supporting stellate ganglion block efficacy and safety for this condition. \\ Methods: Retrospective study on ultrasound-guided stellate ganglion blocks for electrical storm \\ investigating patient clinical characteristics, immediate and long-term outcomes, and procedure related \\ complications. \\ Results: Four (75\% men) critically ill patients maximized on standard antiarrhythmic therapy underwent \\ six bedside ultrasound-guided stellate ganglion block procedures. All blocks were unilateral left-sided, two \\ patients underwent repeat blocks for arrythmia reoccurrence. All patients experienced at least 12 hours \\ free of ventricular arrhythmias with two thirds lasting beyond 24 hours. There were no observed \\ complications. \\ Conclusions: Ultrasound-guided stellate ganglion block is an effective and safe temporizing treatment \\ option for electrical storm. Our institution-specific multidisciplinary guidelines were helpful in providing \\ guidance for the use of stellate ganglion blocks in electrical storm.

\section{Keywords} \\ percutaneous stellate ganglion block, electrical storm, resistant ventricular tachycardia, ultrasound guided \\ regional anesthesia, resistant ventricular arrhythmia, neuromodulation

\section{Creative Commons License}

\section{(c) (i) (2)}

This work is licensed under a Creative Commons Attribution-Noncommercial-No Derivative Works 4.0 License. 


\section{Experience Treating Electrical Storm Using an Ultrasound-Guided Stellate Ganglion Blockade \\ TA Nicholas', LJ Zehr', HJ Wang ${ }^{1}, 2$, DR Anderson ${ }^{3}$, SJ Lisco' ${ }^{1}$}

${ }^{1}$ University of Nebraska Medical Center, College of Medicine, Department of Anesthesiology.

'University of Nebraska Medical Center, College of Medicine, Department of Cellular and Integrative Physiology.

${ }^{3}$ University of Nebraska Medical Center, College of Medicine, Department of Internal Medicine, Division of Cardiovascular Medicine.

https://doi.org/10.32873/unmc.dc.gmerj.3.1.004

\section{Abstract}

Introduction: Electrical storm is a lifethreatening condition in an often medically complex patient population. Pharmacologic ultrasound-guided stellate ganglion blockade is a treatment option in combination with maximized systemic antiarrhythmic medications. There is an emerging body of case reports supporting stellate ganglion block efficacy and safety for this condition.

Methods: Retrospective study on ultrasound-guided stellate ganglion blocks for electrical storm investigating patient clinical characteristics, immediate and long-term outcomes, and procedure related complications.

Results: Four (75\% men) critically ill patients maximized on standard antiarrhythmic therapy underwent six bedside ultrasoundguided stellate ganglion block procedures. All blocks were unilateral and left-sided, with two patients undergoing repeat blocks for arrythmia reoccurrence. All patients experienced at least 12 hours free of ventricular arrhythmias with two-thirds lasting beyond 24 hours. There were no observed complications.

Conclusions: Ultrasound-guided stellate ganglion block is an effective and safe temporizing treatment option for electrical storm. Our institution-specific multidisciplinary guidelines were helpful in providing guidance for the use of stellate ganglion blocks in electrical storm.

\section{Introduction}

Electrical storm (ES) is a life-threatening condition associated with multiple episodes of ventricular arrhythmias resulting in hemodynamic instability and possibly implantable cardioverter-defibrillator (ICD) therapy including shock or anti-tachycardia pacing. Although the definition of electrical storm varies, a reasonably accepted definition of this entity is when three or more separate ventricular arrhythmia episodes occur within a 24-hour period. ${ }^{1}$ Importantly, survival from ES is highly dependent upon the presence of an ICD and rhythm restoration, and/or mechanical hemodynamic support. In this regard, 4 percent of post-infarction patients in whom an ICD was placed will develop electrical storm. ${ }^{2}$ The incidence is significantly higher, at nine percent, in patients who have received placement of a left ventricular assist device (LVAD). ${ }^{3}$ ES occurred $63 \%$ of the time during the first month post-implantation. ${ }^{3}$ The occurrence of ES in any patient is a serious event; graver for LVAD recipients in whom mortality rates as high as $30 \%$ have been reported within 15 days of the arrhythmic event. $^{3}$

Standard therapy of ES typically involves suppression of arrhythmias by antiarrhythmic drug therapy, identification of reversible causes, mechanical cardiac support, cardiac ablation, and a reduction of sympathetic tone. Examples of reversible causes include decompensated heart failure, myocardial ischemia, metabolic disturbances, and inadequate ICD programming. Sympathetic tone reduction can be achieved by betablockade and/or deep sedation, the latter requiring intubation and mechanical ventilation. Less commonly, alternative approaches such as thoracic epidural analgesia, surgical left sympathetic cardiac denervation, and percutaneous stellate ganglion pharmacologic blockade have been employed. Commonly, such options are not viable since these patients are frequently anticoagulated or hemodynamically unstable and unable to undergo a surgical procedure such as sympathectomy.

Percutaneous stellate ganglion blockade for the treatment of ES has been reported in the literature mainly as retrospective case reports and small case series..$^{4-9}$ Once a rare therapeutic intervention for ES, this novel approach to sympathetic tone reduction is emerging as a safe and effective treatment option for ES patients resistant to emergency intravenous drug therapy or for those requiring temporizing measures until a more definitive procedural therapy, such as cardiac ablation, can be performed. This article will review our recent institutional experience on the use of percutaneous stellate ganglion blockade in addition to standard treatment strategies. We report University of Nebraska Medical Center (UNMC) practice of utilizing ultrasound guided stellate ganglion block (USGB) for the treatment of ES and its effect on the ventricular arrhythmia (VA) free period, incidence of block complications, and rate of survival to discharge.

\section{Materials and Methods}

Design and Setting: This retrospective case series identified all patients who had received an USGB for the treatment of ES from January 2018 through August 2019 at UNMC. The UNMC Institutional Review Board approved the study design and waived the need for patient consent. UNMC is an academic, quaternary-care institution with 800 licensed beds and annually performs over 200 catheter ablations, 50 ventricular assist devices, 80 ECMO cannulations, and 40 heart transplants.

Study Population: Four patients who had been identified as suffering from ES as defined by $\geq 3$ episodes of sustained VT, VF, or appropriate shocks from an ICD within a 24-hour period were included in the study. ${ }^{10}$ Each patient received at least one USGB. Two patients received repeat USGBs. Patient demographic and clinical data was retrieved from the hospital electronic medical record. A thorough evaluation of the patients' records was performed. Included in this review were progress notes, laboratory values, electrophysiology consult notes, implanted cardiac device interrogations, electrocardiograms, scanned telemetry strips, echocardiograms, pharmaceutical interventions, USGB and other operative procedures, procedural complications, discharge summaries, cardiac and respiratory events, and long-term outcomes.

\section{Arrhythmia Management: At UNMC, USGB treatment guidelines for electrical storm were developed in conjunction with our cardiac electrophysiologists (EP) (Table 1). These guidelines are utilized in conjunction with other standard measures such as identifying and treating reversible causes of ES, ICD interrogation and reprogramming, intubation and deep sedation, antiarrhythmic drugs, VA catheter ablation, and mechanical cardiac support.}

USGB Procedure: Most stellate ganglion blocks are performed at UNMC for chronic pain related issues. The indication for these blocks typically allows for the block to be performed in an outpatient setting by our chronic pain service during regular clinic hours. However, patients suffering from electrical storm may require emergent stellate ganglion blockade. Therefore, our acute 
pain service (APS) provides 24/7 coverage for these patients. Once a patient has been identified by our cardiac electrophysiologists (EP), the acute pain service is consulted. At UNMC, acute pain service providers utilize ultrasound guidance for stellate ganglion block. Following our established USGB guidelines (Table 1), the patient must be in an intensive care setting where appropriate monitoring and vasopressor support is readily available. The blocks are performed by either a staff APS anesthesiologist or by a directly supervised senior anesthesiology resident on the APS service. All blocks are performed at the patient's bedside. Initially, a left sided block is performed in order to reduce the risk of hypotension observed commonly with right sided and bilaterally SGB. ${ }^{11}$ During the lateral approach to the stellate ganglion, the operator uses a linear ultrasound probe $5-18 \mathrm{MHz}$ (GE Logiq Er7) to identify carotid artery, left internal jugular vein, inferior thyroid artery, longus coli muscle, vertebral artery, anterior scalene muscle, prevertebral fascia, transverse and vertebral body of C6 and C7 (Fig. 1). Color flow doppler is used to pre-scan the intended needle trajectory to avoid inadvertent vascular puncture. The skin is anesthetized with $2-5 \mathrm{~mL}$ of $1 \%$ lidocaine. A 20 -gauge, $100 \mathrm{~mm}$ nerve block needle (BBraun Ultraplex $360^{\circledR}$ ) is advanced in a posterior-to-anterior direction. Once the prevertebral fascia has been pierced a small amount of saline is used to hydro-dissect the fascial planes and verify appropriate needle tip location. After a negative aspiration, local anesthetic and dexamethasone are injected. Either the C6 or C7 vertebral body level is used based upon resolution and presence of vascular entities. As established in the USGB guidelines, if the patient does not experience response within 4 hours, then a right sided block is performed. Bilateral blocks are only performed in intubated patients due to the risk of bilateral phrenic nerve palsy. The block is repeated at 24 and 72 hours dependent on the patient response and condition.

Statistical Analysis: Descriptive statistics were utilized. Continuous data are presented as mean $\pm \mathrm{SD}$ and categorical data are presented as numbers or percentages.

\section{Results}

A total of four patients (age, $63 \pm 9$ years; $75 \%$ men) received a USGB for the diagnosis of electrical storm. The patients' baseline demographic characteristics are shown in (Table 2). A total of six USGBs were performed. All patients received a left sided USGB. The preferred block solution was $10 \mathrm{ml}$ of $0.25 \%$ bupivacaine $+5 \mathrm{mg}$ dexamethasone particle-free, which was utilized in five of

Table 1.

Guidelines for ultrasound-guided stellate ganglion block (USGB) blockade for Electrical Storm

\begin{tabular}{l}
\hline EP cardiology will determine if a stellate ganglion block is indicated \\
\hline APS will be consulted to urgently place the USGB \\
\hline Left sided SGB will initially be performed \\
\hline Right-side USGB will be performed if no decrease in VA burden within 4 hours \\
\hline USGB will be repeated at 24 hours and 72 hours \\
\hline Interval may be adjusted depending on the patient response and cardiovascular status \\
\hline Prior response to laterality will determine subsequent laterality \\
\hline Need for repeat USGB after 72 hours will be determined by the EP cardiologist \\
\hline APS provider will perform the USGB at bedside under the following conditions: \\
\hline Intensive care setting \\
\hline Standard monitors and ACLS resuscitative equipment \\
\hline Norepinephrine solution at bedside \\
\hline Initial USGB will be performed with $0.25 \%$ bupivacaine, $10 \mathrm{ml}$ per ganglion and $5 \mathrm{mg}$ Dexamethasone per \\
ganglion \\
\hline Repeat block at 24 hours will be performed using only $0.25 \%$ bupivacaine PF, $10 \mathrm{ml}$ per ganglion \\
\hline Dexamethasone 5 mg will only be utilized with the 1 st block and at 72 hours \\
\hline
\end{tabular}

\section{$\mathrm{EP}=$ Electrophysiology}

APS $=$ Acute Pain Service

USGB= Ultrasound-guided stellate ganglion block

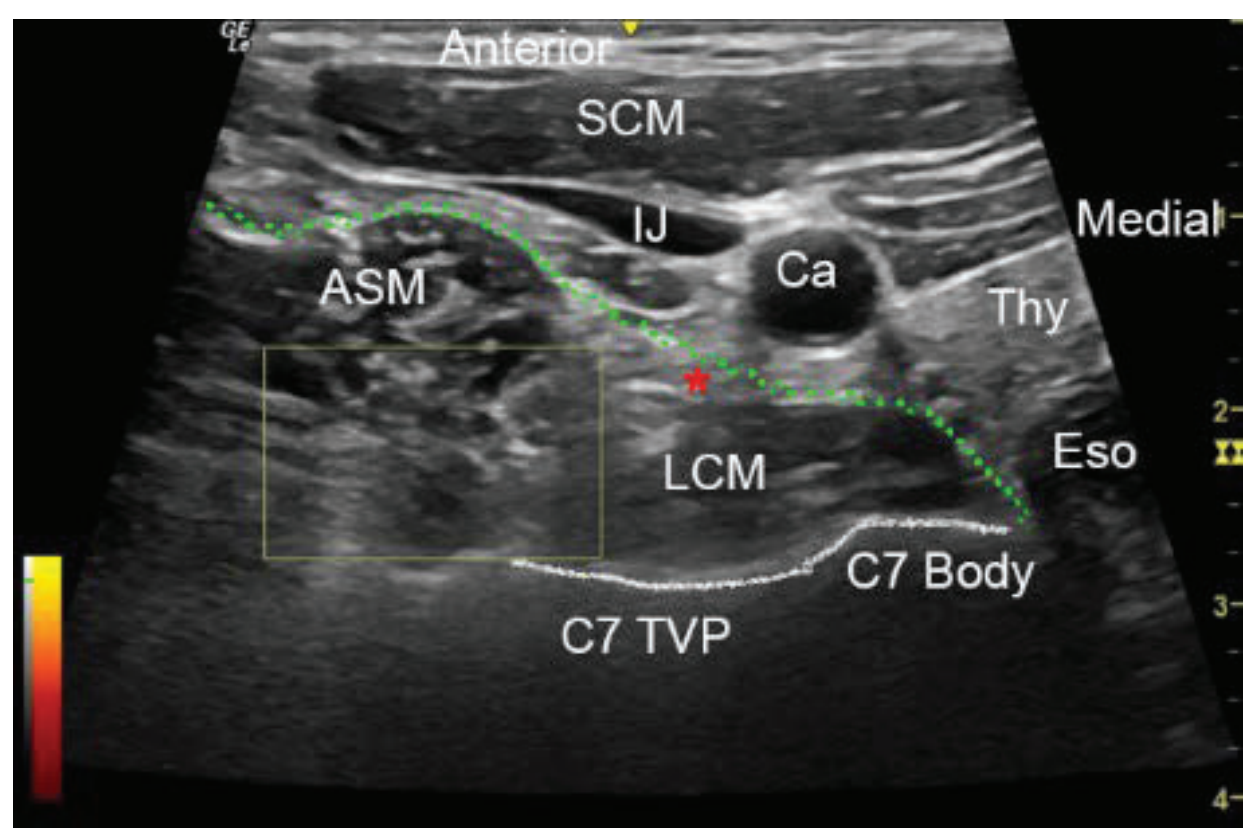

Figure 1. Ultrasound image for a left stellate ganglion block. SCM (sternocleidomastoid muscle), LCM (longus coli muscle), IJ (internal jugular vein), Ca (carotid artery), Thy (thyroid), Eso (esophagus), ASM (anterior scalene muscle), C7 body (C7 vertebral body), C7 TVP (C7 transverse vertebral process). Green line traces the prevertebral fascia. Red star below prevertebral fascia identifies target for injection. The star represents the target for solution injection. Yellow box with scale demonstrates power doppler imaging (PDI) scanning for vertebral artery (not identified).

the six blocks. Lipospheric bupivacaine $39.9 \mathrm{mg}+2 \mathrm{ml} 0.25 \%$ bupivacaine was used in one repeated block. The patients' baseline demographic characteristics are shown in (Table 2). Three of the six blocks were performed on patients who were intubated, systemically anticoagulated, and receiving vasopressor support. The block was repeated in two patients for VA recurrence. No patient received a bilateral USGB. No patient suffered from any block-related complication. No bleeding complications were noted considering half of the blocks occurred during therapeutic levels of anticoagulation. No block resulted in increased vasopressor dosage or initiation of vasopressor infusion. 
Table 2.

Demographics.

\begin{tabular}{|c|c|c|c|}
\hline Characteristics & $\begin{array}{l}\text { Totals } \\
\text { (mean } \pm \mathrm{SD} / \%)\end{array}$ & Characteristics & $\begin{array}{l}\text { Totals } \\
\text { (mean } \pm \mathrm{SD} / \%)\end{array}$ \\
\hline \# of patients & 4 & \multicolumn{2}{|l|}{ Pharmaceutical intervention } \\
\hline Gender male & $75 \%$ & Deep sedation & $67 \%$ \\
\hline Age & $63 \pm 9$ & No. of antiarrhythmic drugs & $2.8 \pm 0.4$ \\
\hline Body mass index & $33 \pm 5$ & Vasopressor support pre-block & $50 \%$ \\
\hline Hypertension & 100 & No. of vasopressor drugs & $0.8 \pm 1.2$ \\
\hline Diabetes mellitus & 0 & \multirow{3}{*}{$\begin{array}{l}\text { Vasopressor support increased } \\
\text { or initiated immediately } \\
\text { following block }\end{array}$} & \multirow[t]{3}{*}{$0 \%$} \\
\hline Kidney disease & $75 \%$ & & \\
\hline Atrial fibrillation/atrial flutter & $25 \%$ & & \\
\hline $\begin{array}{l}\text { Echocardiography LVEF pre- } \\
\text { block\% }\end{array}$ & $20 \% \pm 8$ & $\begin{array}{l}\text { Presence of therapeutic } \\
\text { anticoagulation }\end{array}$ & $50 \%$ \\
\hline Prior Ventricular arrhythmias & $50 \%$ & \multicolumn{2}{|l|}{ Morbidity/mortality } \\
\hline $\begin{array}{l}\text { Cardiac surgery within } 2 \text { wk. } \\
\text { Ischemic cardiomyopathy }\end{array}$ & $\begin{array}{l}75 \% \\
75 \%\end{array}$ & $\begin{array}{l}\text { Hospital death within } 72 \text { hrs of } \\
\text { block }\end{array}$ & $25 \%$ \\
\hline Nonischemic cardiomyopathy & $25 \%$ & Survival to discharge & $50 \%$ \\
\hline ICD present & $50 \%$ & Survival at 3 months & $50 \%$ \\
\hline \multicolumn{2}{|l|}{ Laboratory values } & Patients free of VA after & $50 \%$ \\
\hline Potassium & $4.0 \pm 0.9$ & discharge from hospital & \\
\hline Creatinine & $1.6 \pm 0.8$ & \multicolumn{2}{|l|}{ Nerve block } \\
\hline Magnesium & $2.3 \pm 0.2$ & \# USGB performed & 6 \\
\hline INR & $\begin{array}{l}2.3 \pm 0.2 \\
1.7 \pm 0.8\end{array}$ & \# Repeated blocks & 2 \\
\hline Platelets & $161.7 \pm 70$ & \multirow{3}{*}{$\begin{array}{l}\text { Supervised resident performed } \\
\text { Unilateral left side SGB } \\
\text { Bilateral SGB }\end{array}$} & $50 \%$ \\
\hline \multicolumn{2}{|l|}{ Indication for block } & & $100 \%$ \\
\hline \multirow{6}{*}{$\begin{array}{l}\text { VT only } \\
\text { VT + VF } \\
\text { Diagnosis of electrical storm } \\
\text { Episodes of VT/VF PRE-block } \\
\text { Number of ICD, external } \\
\text { defibrillation shocks, or ATP in } \\
24 \text { hr. pre-block period }\end{array}$} & $67 \%$ & & $0 \%$ \\
\hline & $33 \%$ & \multirow{4}{*}{$\begin{array}{l}\text { Block complication } \\
\text { Horners syndrome documented } \\
\text { USGB solution used: } 10 \mathrm{ml} \\
0.25 \% \text { bupivacaine }+5 \mathrm{mg} \\
\text { dexamethasone }\end{array}$} & \multirow{2}{*}{$\begin{array}{l}0 \% \\
33 \%\end{array}$} \\
\hline & $\begin{array}{l}33 \% \\
100 \%\end{array}$ & & \\
\hline & $\begin{array}{l}100 \% \\
5 \pm 3\end{array}$ & & \multirow[t]{2}{*}{$83 \%$} \\
\hline & $2 \pm 3$ & & \\
\hline & & Period of VA free time post & $55 \pm 78$ \\
\hline \multicolumn{2}{|l|}{ Mechanical support } & \multirow{2}{*}{$\begin{array}{l}\% \text { of blocks resulting in a } 12 \mathrm{hr} \\
\text { VA free period }\end{array}$} & \multirow{2}{*}{$100 \%$} \\
\hline IABP & $0 \%$ & & \\
\hline LVAD & $50 \%$ & \multirow{2}{*}{$\begin{array}{l}\% \text { of blocks resulting in a } 24 \mathrm{hr} \\
\text { VA free period }\end{array}$} & \multirow[t]{2}{*}{$67 \%$} \\
\hline ECMO & $50 \%$ & & \\
\hline \multirow[t]{2}{*}{ Intubation pre block } & $67 \%$ & $\begin{array}{l}\% \text { of blocks resulting in a } 48 \mathrm{hr} \\
\text { VA free period }\end{array}$ & $17 \%$ \\
\hline & & $\begin{array}{l}\% \text { of blocks resulting in a } 72 \mathrm{hr} \\
\text { VA free period }\end{array}$ & $17 \%$ \\
\hline
\end{tabular}

LVEF= left ventricular ejection fraction

$I C D=$ implanted cardiac defibrillator INR= international normalized ratio $\mathrm{VT}=$ ventricular tachycardia
$\mathrm{VT}+\mathrm{VF}=$ ventricular tachycardia and ventricular fibrillation ATP $=$ antitachycardia pacing $\mathrm{IABP}=$ intra-aortic balloon pump $L V A D=$ left ventricular assist device
$\mathrm{ECMO}=$ extracorporeal membrane oxygenator $\mathrm{VA}=$ ventricular arrhythmia $\mathrm{ml}=$ millilite $\mathrm{mg}=$ milligram
All individual blocks resulted in at least a 12-hour VA free period. Two-thirds of the individual blocks resulted in a 24-hour VA free period. Two patients survived to discharge and were VA free upon discharge. Two of the four patients were transitioned to compassionate withdrawal of care. This resulted in their death on post-operative day 3 and 5 respectively. These patients developed severe refractory biventricular failure and multi-organ dysfunction following their respective index surgeries: an on-pump multi-vessel coronary artery bypass grafting $(\mathrm{CABG})$ and an ascending arch repair plus multi-vessel CABG with full circulatory arrest, respectively. Both patients received initiation of ECMO intraoperatively. Care was withdrawn by family due to futility of care in these patients. Notably, no death occurred within 48 hours of USGB. Of the 2 surviving patients, one underwent successful ventricular ablation 2 days after the USGB. Both surviving patients ultimately underwent successful heart transplantation.

\section{Discussion}

Four patients underwent six successful USGB at our institution by the APS. All blocks were judged efficacious based on clinical and electrical criteria. No complications directly related to block placement were observed. This case series is significant for several reasons. First, in all patients, USGB was utilized for rescue in the context of maximal supportive therapy. Second, a benefit was observed following each procedure with at least a 12-hour VA free interval noted following block placement. Finally, half of our blocks were performed in patients who were systemically anticoagulated without notable bleeding complications. Taken in sum, we believe USGB to be a potentially viable therapeutic and safe intervention for rescue of refractory ES.

No prospective randomized clinical trials exist in the literature evaluating the benefits of stellate ganglion block for the treatment of recurrent VT or ES. However, our review of the literature identified several small retrospective case series employing stellate ganglion block as a treatment option for recurrent VT or ES. ${ }^{4,9,12}$ While randomized trials are always preferable and certainly needed, in this context, such a study would be difficult to complete as often ES patients are critically ill and have maximized pharmacologic treatment and mechanical support options. In this situation, stellate ganglion block is performed as a final option or life saving measure.

The ability to provide a potentially lifesaving treatment option for patients suffering from ES was motivation for our team to develop clinical guidelines for the use of USGB at UNMC. Similar to other institutions' protocols, the multidisciplinary guidelines were developed in junction with EP Cardiology, Acute Pain Anesthesiology, Critical Care Anesthesiology, and Cardiothoracic Surgery. These guidelines helped educate and inform providers as to the availability of the USGB as a treatment option in ES patients. Standardized guidelines based upon current literature helped to assure that the USGB was appropriately and maximally utilized at our training institution. For instance, many treatment providers do not consider the need for repeat or bilateral USGB for recurrence of VT. Also important are the safety measures embedded in the guidelines assuring complications are avoided. The paucity of observed complications in our series is similar to other case reports. Currently, the largest published case series of 30 patients involving 38 blocks reported a solitary complication of a sore throat after SGB, notable considering $50 \%$ of the patients were fully anticoagulated with warfarin at time of the procedure. ${ }^{9}$ Most reported procedure operators were anesthesiologists. One case series of similar size to ours was performed by EP cardiologists ${ }^{4}$. Compared to other studies, the observed 50\% mortality during hospitalization is higher but difficult to interpret due to the premorbid condition of two of our patients.

Various volumes and medications have been reported in prior studies which typically included bupivacaine or lidocaine alone or in varying combinations without standardization. ${ }^{4,9}$ However, we chose to 
standardize our block medications. Five of the 6 blocks were performed using 10 $\mathrm{ml}$ of $0.25 \%$ bupivacaine plus $5 \mathrm{mg}$ of dexamethasone. Dexamethasone was added to our block mixture based upon research which identified that macrophage activation in the stellate ganglion contributes to arrhythmogenesis in bleomycin-induced acute lung injury..$^{13}$ The use of dexamethasone as an adjuvant for nerve blocks is quite common. However, the underlying mechanism of prolonged nerve blockade is not clearly understood. It is our hope that the addition of the medication would reduce stellate neuroexcitation through its macrophage inhibitory effects thereby reducing the need for repeated USGB.

The observed reduction VA in episodes was similar to other reports. ${ }^{9,14}$ One patient received lipospheric bupivacaine and bupivacaine HCL because of worsening severe coagulopathy and it was felt that the opportunity to safely repeat a block would not exist. This patient had resolution of ventricular tachycardia for 24 hours. The VT recurred in the operating room with direct cardiac manipulation during attempted VA ECMO decannulation. However, the patient did not have recurrence of VT for rest of the hospitalization. The use of lipospheric bupivacaine for a stellate ganglion block has been reported one other time in literature. ${ }^{15}$ The focus of promoting a sodium channel blockade at the stellate ganglion using local anesthetics could be augmented by the addition of clonidine which has been reported as a local anti-inflammatory agent in addition to its $\alpha 2$ adrenergic effect. ${ }^{16}$

\section{References}

1 Gao D, Sapp JL. Electrical storm: definitions, clinical importance, and treatment. Curr Opin Cardiol. 2013;28:72-9.

2 Sesselberg HW, Moss AJ, McNitt S, et al. Ventricular arrhythmia storms in postinfarction patients with implantable defibrillators for primary prevention indications: a MADIT-II substudy. Heart Rhythm. 2007;4:1395-402.

3 Martins RP, Leclercq C, Bourenane H, et al. Incidence, predictors, and clinical impact of electrical storm in patients with left ventricular assist devices: New insights from the ASSIST-ICD study. Heart Rhythm. 2019;16:1506-12.

4 Cardona-Guarache R, Padala SK, Velazco-Davila $\mathrm{L}$, et al. Stellate ganglion blockade and bilateral cardiac sympathetic denervation in patients with life-threatening ventricular arrhythmias. J Cardiovasc Electrophysiol. 2017;28:903-8.

5 Hayase J, Patel J, Narayan SM, Krummen DE. Percutaneous stellate ganglion block suppressing VT and VF in a patient refractory to VT ablation. $J$ Cardiovasc Electrophysiol. 2013;24:926-8.

6 Kumar A, Sinha C, Kumar A, Sinha AK. Ultrasoundguided stellate ganglion block for resistant ventricular tachycardia. Saudi J Anaesth. 2017;11:372-3.

7 Scanlon MM, Gillespie SM, Schaff HV, Cha YM, Wittwer ED. Urgent Ultrasound-Guided Bilateral Stellate Ganglion Blocks in a Patient With Medically

\section{Study Limitations}

This small case series study is limited by its retrospective design. The complex and somewhat premorbid patient population also varied with respect to concurrent medical therapy, ICD presence, surgical interventions, mechanical circulatory support, use of general anesthesia, and attempts at catheter ablation. Even though guidelines exist at our institution, the guidelines were adjusted based upon the patients' unique clinical status and treating providers' personal bias and comfort with the use of USGB. However, these guidelines provided a general basis of agreement and possibly a standard of care which can be applied to future randomized trials. Another deficit of this study was a lack of documentation of Horner's Syndrome or ipsilateral extremity temperature change. Documentation of Horner's Syndrome only occurred in two of the six blocks. This may not be as important since ultrasound guidance allows for real-time visualization of local anesthetic deposit and has been shown to reliably provide stellate blockade when compared to stellate ganglion block using anatomic landmarks. ${ }^{17}$ Another deficit at our facility is the fact that our telemetry monitoring system does not allow for retrospective review of raw continuous data. Telemetry strips are printed and manually scanned into the patient chart (Fig 2.) making statistical analysis of continuous data including 24-hour ventricular arrhythmias burden impossible.

\section{Conclusions}

USGB provided at least a 12-hour VA free period in 4 of 4 patients who were suffering from electrical storm. None of these complex patients incurred complications related to the block. USGB should be considered as a safe adjunctive therapy for patients suffering from electrical storm who are maximized on standard therapy. Individual institutional guidelines for the use of stellate ganglion block should be established to standardize and safely accomplish this procedure.

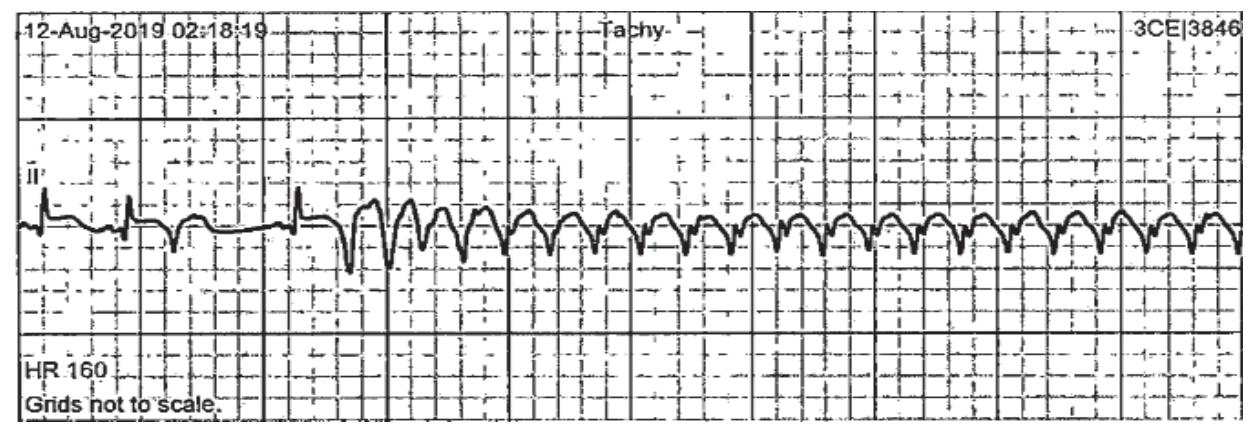

Figure 2. Scanned patient telemetry strip identifying onset of ventricular tachycardia.

Refractory Ventricular Arrhythmias. Crit Care Med. 2015;43:e316-8

8 Smith DI, Jones C, Morris GK, Kralovic S, Massey HT, Sifain A. Trial ultrasound-guided continuous left stellate ganglion blockade before surgical gangliolysis in a patient with a left ventricular assist device and intractable ventricular tachycardia: a pain control application to a complex hemodynamic condition. ASAIO Journal. 2015;61:104-6.

9 Tian Y, Wittwer ED, Kapa S, et al. Effective use of percutaneous stellate ganglion blockade in patients with electrical storm. Circ Arrhythm Electrophysiol. 2019; 12:e007118.

10 Al-Khatib SM, Stevenson WG, Ackerman MJ, et al. 2017 AHA/ACC/HRS guideline for management of patients with ventricular arrhythmias and the prevention of sudden cardiac death: a report of the American College of Cardiology/American Heart Association Task Force on Clinical Practice Guidelines and the Heart Rhythm Society. $J A C C$. 2018;72:e91-e220.

11 Yokota S, Taneyama C, Goto H. Different effects of right and left stellate ganglion block on systolic blood pressure and heart rate. Open Journal of Anesthesiology. 2013;3:143.
12 García-Morán E, Sliwinski-Herrera F, Cortes-Villar C, Sandín-Fuentes M, Pastor Báez G, San Román A. Refractory electrical storm: a role for transient sympathetic blockade. J Revista Española de Cardiología. 2016;69:76-8.

13 Adam R, Gao L, Hong J, Zucker IH, Lisco SJ, Wang H. Abstract P2004: Neural Inflammation in Stellate Ganglia Mediates Lung Injury-Induced Arrhythmogenesis. J Hypertension. 2019;74:AP2004AP.

14 Fudim M, Boortz-Marx R, Ganesh A, et al. Stellate ganglion blockade for the treatment of refractory ventricular arrhythmias: A systematic review and meta-analysis. Journal of Cardiovascular Electrophysiology. 2017;28:1460-7.

15 Qureshi AI, Waqas MA, Jadhav V, Saleem MA, Campbell J, Wallery SS. Long acting liposomal bupivacaine for percutaneous sympathetic stellate ganglion blockade: a technical note. JVIN. 2017;9:49.

16 Romero-Sandoval EA, McCall C, Eisenach JC. $\alpha 2$-Adrenoceptor stimulation transforms immune responses in neuritis and blocks neuritis-induced pain J Neurosci. 2005;25:8988-94.

17 Kapral S, Krafft P, Gosch M, Weinstabl C, Fleischmann D. Ultrasound imaging for stellate ganglion block: direct visualization of puncture site and local anesthetic spread: a pilot study. Reg Anesth Pain Med. 1995;20:323-8. 